\title{
An Audit of Uterovaginal Prolapse in Enugu, Southeast Nigeria
}

\author{
OKEKE TC ${ }^{*}$, ANI VC, EZENYEAKU CCT, IKEAKO LC, ENWEREJI JO, EKWUAZI K \\ Department of Obstetrics \& Gynaecology, University of Nigeria Teaching Hospital (UNTH), Enugu, Nigeria \\ *Corresponding author: ubabiketochukwu@yahoo.com
}

Received January 15, 2013; Revised February 02, 2013; Accepted February 16, 2013

\begin{abstract}
A retrospective study of utero-vaginal prolapse to determine the frequency and determinants of uterovaginal prolapse, degrees and its complications at the University of Nigeria Teaching Hospital (UNTH) Enugu, Nigeria between January 1, 2005 and December 31, 2009. The prevalence of uterovaginal prolapse was 3.4\%. Thirty three $(66 \%)$ of them were postmenopausal. Multiparity was a significant determinant as $74 \%$ of them were grandmultiparous. The commonest symptom was 'something coming down the vagina' in $96 \%$ of the study subjects. Second degree prolapse was the commonest type of presentation (48\%) and the definitive treatment modality was vaginal hysterectomy with pelvic floor repair (44\%). Multiparity, prolonged labour and unsupervised deliveries are significant determinants. Uterovaginal prolapse is primarily a common gynaecological condition of the parous and elderly postmenopausal women associated with a decreased body image and quality of life. Education of women, women empowerment, effective antenatal care, supervised hospital deliveries, and limiting the family size by efficient contraception deserve priority attention to prevent this social malady.
\end{abstract}

Keywords: Genital prolapse, vaginal hysterectomy, pelvic floor repair, determinants, Enugu-Nigeria

\section{Introduction}

Uterovaginal prolapse is the descent of the uterus/cervix through the vaginal canal [1]. It is due to defects in the support structures of the uterus and vagina namely the uterosacral ligaments, the cardinal ligaments complex and connective tissue of the urogenital membrane [2].

The true incidence of this disorder is not known because many of the cases are asymptomatic and many women feel shy to complain of uterovaginal prolapse $[3,4]$. Some degree of uterovaginal prolapse is seen in 50\% of parous women with $10-20 \%$ of these causing symptoms [2].

The development of uterovaginal prolapse is multifactorial [5]. Pelvic floor defects may develop as a result of repeated pregnancies and childbirth and are caused by the stretching and tearing of the endopelvic fascia, levator ani muscles and perineal body [6].

Pregnancy itself without vaginal birth has been sited as a risk factor as well [6].

Multiparous women are at particular risk for pelvic organ prolapse [7]. Hypooestrogenism and genital atrophy also play important contributory roles in the pathogenesis of prolapse [8].

When compared with vaginal delivery, caesarean section has a protective effect in the development of genital prolapse [9].

Certain factors are considered in the management of uterine prolapse such as age, the desire for preservation of reproductive function, the desire for preservation of coital function, general medical status, previous attempts at surgical correction, symptomatology and physical examination findings [8].

The definitive treatment is surgery. Vaginal hysterectomy with pelvic floor repair is offered to patients who have completed their family size. Conservative surgery (Manchester repair) is offered to those where reproductive function is desired $[3,10]$. Leforte's operation is an option in the patients who no longer desire sexual functions or are too old to withstand vaginal hysterectomy $[3,10]$. Pessaries can be used in patients not fit for surgery or early in pregnancy.

Uterovaginal prolapse affects multiparous and elderly women and the cost of its management is substantial [11].

The aim of this study was to determine the frequency, determinants of uterovaginal prolapse, types and its complications at the University of Nigeria Teaching Hospital, Enugu - Nigeria.

\section{Materials and Methods}

This was a retrospective study of uterovaginal prolapse at the University of Nigeria Teaching Hospital, Enugu Nigeria between January 1, 2005 and December 31, 2009. Data was retrieved from gynaecological ward admission register, case files, theatre records and ward reports of the 50 women who were treated for $\mathrm{U}-\mathrm{V}$ prolapse.

The medical records were reviewed by trained staff using pre-established and piloted data extraction forms. Information sort were sociodemographic characteristics (age, parity, occupation, tribe, menopausal status), presenting complaint, duration of symptoms, degrees of prolapse, management modality and outcome, complications as well as operative findings. The data were analyzed by descriptive and inferential statistics using the 
statistical package for social science (SPSS) version 12 and the results expressed in descriptive statistics by simple percentages with frequency tables and pie chart.

\section{Results}

During the five-year period, there were a total of 1488 gynaecological admissions, 50 of which were different degrees of uterovaginal prolapse giving a prevalence of $3.4 \%$.

The mean age at presentation was 49.9 years with a range of $8-82$ years. $82 \%(41 / 50)$ of them were at least 40 years old while $18 \%$ were below 40 years as was shown in Table 1. $96 \%$ of the women had previous vaginal delivery and their mean parity was 5.2 as was shown in Table 2. 66\% (33/50) of the women were postmenopausal while $34 \%(17 / 50)$ were premenopausal as was shown in Table 3. Two percent of them was premenarchial and had urethral caruncle with mucosal prolapse. The commonest presenting symptom was "something coming down the vagina" in $96 \%$ of the women. $60 \%$ of the women were farmers/housewives, $32.0 \%$ were traders, $6.0 \%$ were civil servants and $2 \%$ of the women were students and unmarried.

Table 1. (Age Distribution of Patients)

\begin{tabular}{|l|l|l|}
\hline \multicolumn{3}{|c|}{ Table 1. (Age Distribution of Patients) } \\
\hline$<40$ & Frequency & Percentage \\
\hline$\geq 40$ & 9 & $18 \%$ \\
\hline Total & 41 & $82 \%$ \\
\hline
\end{tabular}

Table 2. (Parity of the patients)

\begin{tabular}{|l|l|l|}
\hline \multicolumn{1}{|c|}{ Table 2. (Parity of the patients) } \\
\hline Parity & Frequency & Percentage \\
\hline Para 0 & 1 & 2 \\
\hline Para 1-4 & 12 & 24 \\
\hline Para 5 and above & 37 & 74 \\
\hline Total & 50 & 100 \\
\hline
\end{tabular}

Table 3. (Menopausal status of the patients)

\begin{tabular}{|l|l|l|}
\hline Menopausal state & Frequency & Percentage \\
\hline Pre menopause & 17 & 34 \\
\hline Post menopause & 33 & 66 \\
\hline Total & 50 & 100 \\
\hline
\end{tabular}

Second degree prolapse $48 \% \quad(24 / 50)$ was the commonest type followed by $1^{\text {st }}$ degree $36 \%$ (18/50) and $3^{\text {rd }}$ degree type accounted for $16 \%(8 / 50)$ as was shown in Figure 1. There was no vault prolapse. Cystocele was seen in $64 \%(32 / 50)$ of them, rectocoele in $16 \%(8 / 50)$ and urethrococle in $2 \%(1 / 50)$ of the women. There was no enterocoele. The mean duration of symptoms was 5.3 years. $44 \%$ of the women had vaginal hysterectomy with pelvic floor repair. Manchester repair was done for $2 \%$ of them while $12 \%$ had pessary insertion. Two percent had urethral caruncle exicision. Four percent had total abdominal hysterectomy and bitateral salpingoophorectomy since they had cervical intraepithelial neoplasm grade III. 36\% refused to undergo surgery and absconded. None of the patients had significant post operative complications. No maternal death was recorded.

\section{Discussion}

The prevalence of $3.4 \%$ for uterovaginal prolapse was found in this study. This was similar to that of Port Harcourt study (3.7\%) [3] and higher than that of Nnewi study $(2.1 \%)$ [12] both in Nigeria, but lower than the rate from a previous population based study $(6 \%)$ [13]. This study is equally lower in prevalence from figures obtained from Ilorin, Nigeria [14,15]. It may be that higher rate of admission of other gynaecological conditions may have reduced the proportion contributed by genital prolapse to gynaecological admissions in this hospital. Other gynecological conditions include uterine fibroids, menstrual abnormality, endometriosis, disorders of puberty, infertility, incontinence, pelvic inflammatory disease, sexually transmitted disease, female genital malignancies (cervix, ovary, endometrium, vulva, vagina etc).

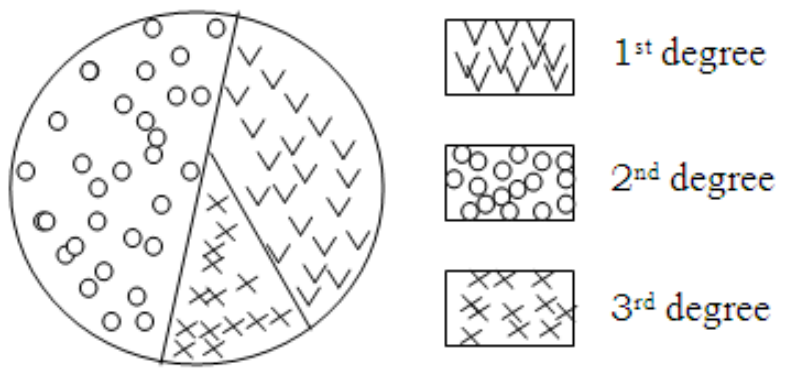

Figure 1. (Pie chart showing the degree of prolapse)

The mean age at presentation was 49.9 years. The condition was commoner in older patients, but less in the younger age group, however, $18 \%$ of them were below 40 years. $66 \%$ of the women were postmenopausal and so had the bulk for uterovaginal prolapse in the study. This was not surprising as hypooestrogenism and genital atrophy are strong risk factors since the supports of the pelvic organs are oestrogen dependent.

Seventy four percent of the women were grandmultiparous and this buttresses the fact that multiparity was a significant risk factor in the development of uterovaginal prolapse [7]. The women going through stress of multiple unsupervised vaginal deliveries at home with prolonged labour is probably the main factor in these women. Unsupervised labour with bearing down efforts before full cervical dilatation weakens the genital supporting ligaments and pelvic fascia [16]. The finding of prolapse in a young multipara and unmarried young girl is documented though uncommon [17]. Forty two percent of the women were farmers and lifted heavy objects for years which were contributory to the development of this condition. The aetiological factors in farmers are as a result of raised intra-abdominal pressure. The mean parity was 5.2 which supported the effect of multiparity.

Most of the women had $2^{\text {nd }}$ degree prolapse $48 \%$, and $36 \%$ had $1^{\text {st }}$ degree prolapse. They however presented relatively late as the mean duration of symptoms was 5.3 years. Uterovaginal prolapse rarely occurs in isolation as there was reported cystocoele in $64 \%$ of the women and rectocoele in $16 \%$ of the women. The commonest symptom was the feeling of "something coming down the vagina" in $96 \%$ of the women and a significant proportion of them had $2^{\text {nd }}$ degree uterovaginal prolapse. Other symptoms are dysuria, frequency and stress incontinence. Backache and constipation are also reported by some women.

Vaginal hysterectomy and pelvic floor repair are the main definitive treatment in this study (44\%), though some had conservative surgery like Manchester repair 
(2\%), insertion of of pessaries $(12 \%)$ in those still bearing children. $4 \%$ had total abdominal hysterectomy and bilateral salpingoophorectomy as they had associated histologically diagnosed cervical intraepithelial neoplasia grade III.

Long term post operative complications were documented for women who had vaginal hysterectomy with pelvic floor repair. The complications are stress incontinence, genital fistulae, apareunia, dyspareunia, shortened vagina and vaginal stenosis but there were no major complications in the women studied.

The limitation of this study was lack of follow-up and poor documentation of data. Data was scanty and poorly documented.

\section{Conclusion}

Uterovaginal prolapse affects women both in the child bearing age and post menopausal period. Multiparity, prolonged labour, poorly supervised and unsupervised deliveries are significant determinants. Efforts should be geared towards public enlightenment and health education, effective antenatal care, supervised hospital deliveries, limiting of family size and efficient use of contraception in reducing this social malady ravaging our women. Education of women and women empowerment should be accorded the priority it deserves in action and not by mere policy statements.

\section{Disclosure of Interest}

The authors report no conflicts of interest. The authors are responsible for the content and writing of the paper.

\section{References}

[1] Tarney CM, Dorr CH: Relaxation of Pelvic Support In: DeCherney AH, Nathan L (eds) Current Obstetric and
Gynecological Diagnosis and Treatment, 9th Edition. New York McGraw-Hill Companies 2003; 776-797.

[2] Robinson D. Urogenital Prolapse, In: Luesley DM, Baker PN (eds). Obstetrics and Gyaecology: An evidence-based text for MRCOG 1st Edition London, Anorld 2004; 661-70.

[3] John CT. Genital Prolapse. In: Okonofua FE, Odunsi K (eds) Contemporary Obstetrics and Gynaecology for Developing Countries. Benin City, WHARC 2003; 214-226.

[4] Stanton SL. Vaginal Prolapse. In: Edmonds DK (ed) Dewhurt's Textbook of Obstetrics and Gynaecology for Post graduates, 6th Edition: London, Blackwell Science 1999; 462-473.

[5] Jelovsek JE, Maher C, Barber MD. Pelvic organ prolapse lancet 2007; 369(9566): 1027-1038.

[6] Hughes PN, Jackson SR. The Scientific basis of Prolapse. TOG 2000; 2:10-15.

[7] Smith AR, Hosker GL, Warrell DW. The role of partial denervation of the pelvic floor in the aetiology of genitourinary prolapse and stress incontinence of urine. A neurophysiological study. Br J Obstet Gynaecol 1989; 96(1): 24-28.

[8] Obed SA: Pelvic Relaxation In: Kwawukume EY, Emuveyan EE (eds) Comprehensive Gynaecology in the Tropics, 1st Edition. Graphic Packaging Ltd. Accra 2005; 138-146.

[9] Lukacz ES, Lawrence JM, Contreras R, Nager CM, Luber KM. Parity, mode of delivery and pelvic floor disorders. Obstet Gynecol 2006; 107(6):1253-1260.

[10] Menefee SA. Incontinence, Prolapse and disorders of the Pelvic floor. In: Berek JS (ed) Novak's Gynaecology 13th edition, Philadelphia. Lippincott Williams and Wilkins 2002; 645-710.

[11] Subak LL, Waetien LE, Van Den Eedens, Thom DH, Vittinghoff E, Brown JS. Cost of pelvic organ prolapse surgery in the United States. Obstet Gynecol 2001; 98(4): 646-651.

[12] Okonkwo JE, Obiechina NJ, Obionu CN. Incidence of pelvic organ prolapse in Nigerian women. J Nath Med Assoc. 2003; 95(2):132-136.

[13] Rortveit G, Brown JS, Thom DH, Van Den Eeden SK, Creasman JM, Subak LL. Symptomatic pelvic organ prolapsed: prevalence and risk factors in a population-based, racially diverse cohort. Obstet Gynecol 2007; 109(6):1396-1403.

[14] Balogun OR. Genital Prolapse in Ilorin: A-seven year review. Niger J Med 1997: 6(3):77-82.

[15] Anate M, Olatinwo AWO. Genital Prolapse in child bearing age, Manchester repair and subsequent reproductive function. Niger Med Pract 1999: 34(3/4): 47-51.

[16] Onowhakpor EA, Omo-Aghoja LO, Akani CI, Feyi-Waboso P. Prevalence and determinants of uterovaginal prolapse in Southern Nigeria. Niger Med J. 2009; 50(2): 29-32.

[17] Omolayole JA, Akingba JB. Procidentia in adolescence Niger Med J. 1975; 5:277-279. 